\title{
A REPRESENTACCÃO DA ENTIDADE COLETIVA: UMA DISCUSSÃO SOBRE O ENSINO E APRENDIZAGEM
}

\section{THE REPRESENTATION OF THE CORPORATE BODY: A DISCUSSION ON TEACHING AND LEARNING}

Naira Christofoletti Silveiraa

\begin{abstract}
RESUMO
Introdução: o tema principal deste texto é o ensino de catalogação na contemporaneidade e tem como fio condutor uma análise sobre a entidade coletiva e os requisitos necessários à formação de graduados em Biblioteconomia. Objetivo: apresentar pesquisas relacionadas à catalogação e discutir o ensino com base nas normativas destinadas ao ensino superior brasileiro e o papel social do catalogador, desde a sua formação. Metodologia: pesquisa bibliográfica que analisa desde a formação do estudante até a atuação docente. Resultados: há algum tempo se discute que a catalogação estaria mais voltada às características tecnicistas e que as demandas e mudanças da área requerem uma reaprendizagem do ensino de tais conteúdos. Conclusões: o papel social e a formação do catalogador requerem múltiplas ações e para isso se deve explorar todos os elementos propostos do projeto pedagógico, desde disciplinas obrigatórias até as atividades de extensão.
\end{abstract}

Descritores: Catalogação. Entidades coletivas. Representação Descritiva. Ensino Superior

\section{INTRODUÇÃO}

Este trabalho apresenta uma reflexão sobre as perspectivas contemporâneas para o ensino da Representação Documental, com o recorte na Representação Descritiva. Tem como objetivo apresentar pesquisas relacionadas à catalogação e discutir o ensino com base nas normativas destinadas ao ensino superior brasileiro e o papel social do catalogador, desde a sua formação.

Em um primeiro momento, identifica-se a necessidade de se repensar 0

\footnotetext{
a Docente do Departamento de Biblioteconomia da Universidade Federal do Estado do Rio de Janeiro (UNIRIO). E-mail: naira.silveira@unirio.br.
} 
ensino de catalogação, que se apresenta muito pautado na aplicação de uso de regras de códigos de catalogação. Com o crescente uso de tecnologia e modelos conceituais, a catalogação passa a ganhar novos conteúdos, sem a anulação dos conteúdos tradicionais, resultando numa necessidade de ampliação ou de reformulação de conteúdos e métodos de ensino.

Esse movimento de se repensar a catalogação, desde a graduação até a atuação profissional, tem sido tema de discussão nos últimos anos especialmente em eventos da área e grupos de trabalho, destacando o Encontro de Estudos e Pesquisas em Catalogação (EEPC), o Encontro Nacional de Catalogadores (ENACAT), o Grupo de Estudos e Pesquisas em Catalogação (GEPCAT) e o Grupo de Trabalho - Catalogação, formalizado este ano pela Federação Brasileira de Associações de Bibliotecários, Cientistas de Informação e Instituições (FEBAB).

Aliado às mudanças na catalogação, o ensino superior passou por uma reestruturação na legislação. As diretrizes curriculares apresentam maior flexibilização e os projetos pedagógicos dos cursos passam a nortear a formação do graduando e novas demandas são exigidas dos docentes: ensino, pesquisa e extensão.

Com base na pesquisa bibliográfica na BRAPCI foi possível identificar que estudos sobre o ensino e a formação de catalogador ganhou maior destaque nos últimos anos, com pesquisa que envolve desde a graduação como a pósgraduação. Os termos de busca versaram sobre ensino, catalogação e representação descritiva, a busca foi realizada em agosto e setembro de 2020.

O resultado dessa pesquisa bibliográfica pode ser constatada na seção 2 deste texto, na qual aborda especificamente os textos recuperados sobre ensino de representação descritiva. Por ter como recorte a Representação Descritiva, a seção 3 apresenta o conteúdo abordado nessa disciplina relacionado às entidades coletivas, pois acredita-se que esse exemplo poderia refletir melhor a necessidade de estudos sociais, culturais e tecnológicos para o catalogador. A seção 4 apresenta principalmente as normativas sobre cursos de graduação brasileiros, assim como o plano de carreira docente. A última seção apresenta algumas considerações finais resultantes deste trabalho 


\section{A REPRESENTAÇÃO DESCRITIVA: ENSINO E APRENDIZAGEM}

Dentre os vários textos recuperados sobre ensino e aprendizagem em Biblioteconomia, os trabalhos de Castro são sempre mencionados e merecem destaque por sua trajetória acadêmica. Um deles, mesmo com 15 anos de publicação, continua atual. Castro (2005) aponta que a formação do bibliotecário deve transcender o discurso unilateral e unívoco, considerando a sociedade atual, ressaltando a importância de uma análise política e ideológica contemporânea. O bibliotecário não pode ser um simples reprodutor e usuário de tecnologia.

Assim, o processo de ensino e aprendizagem se efetiva através de uma dinamicidade onde os saberes e as práticas estão em fluxo contínuo de (re)significação, ou seja, adaptam-se às necessidades presentes e futuras dos aprendentes (CASTRO, 2005. p. 24).

Embora aborde o ensino e aprendizagem de modo amplo ao bibliotecário, observa-se que as disciplinas de Organização do Conhecimento (OC) têm vivenciado um grande avanço tecnológico nos últimos 50 anos, especificamente após a década de 1990 com os modelos conceituais do universo bibliográfico que aliam 0 desenvolvimento de modelos entidade-relacionamento, influenciados pela Ciência da Computação, como também com a grande oferta de serviços e software digitais. Embora a discussão seja importante e profícua, não seria possível abordá-la de modo profundo neste artigo, por isso, nesta seção se versará especificamente sobre o ensino e aprendizagem em Representação Descritiva, o recorte deste trabalho.

Ortega (2013) aborda um histórico muito rico sobre o ensino de Catalogação, que embora esteja focado principalmente na Universidade Federal de Minas Gerais (UFMG), as fases e características podem ser identificadas em outras escolas de Biblioteconomia no país. O que chama a atenção é a prioridade em se ensinar na graduação a prática de códigos em detrimento de ensino teórico e conceitual e a baixa produção de teses e dissertações defendidas na UFMG com sentido restrito em Catalogação. Muitas vezes identificou-se que a ementa das disciplinas parecia traduzir os capítulos do Código de Catalogação Anglo-Americano. Como considerações finais, essa 
pesquisa apresenta:

O momento que se coloca, na Escola, mas, também, no país, é o da necessidade de ressignificação dos estudos de Organização da Informação, simultaneamente à articulação com as demais subáreas da Ciência da Informação, enquanto movimento que favorece a pesquisa e a formação profissional, assim como a contínua consolidação institucional de escolas e cursos (ORTEGA, 2013, p. 213).

Interessante observar que o ensino de graduação não está distante da pesquisa na pós-graduação, o docente deve ser acima de tudo um pesquisador. Quando se tem um número baixo de teses e dissertações, pode-se inferir que não estão sendo formados docentes pesquisadores na área. Também se observa que a iniciação científica tem como proposta iniciar os estudantes de graduação na pesquisa, traçando assim o começo de uma carreira acadêmica.

$$
\begin{aligned}
& \text { Ao docente interessa a preparação do aluno ingressante para a } \\
& \text { pesquisa em seu ciclo universitário; ao mesmo tempo, o aluno é } \\
& \text { contemplado com a chance de aprender na prática o que é uma } \\
& \text { investigação científica (FRANCELIN, 2016, p. 140). }
\end{aligned}
$$

Nesse sentido, a pesquisa que se inicia na graduação busca formar um arcabouço que possibilite o ingresso na pós-graduação, para uma continuidade de estudos sobre determinadas temáticas. Após a obtenção do título de doutor, atribuído ao término de uma pesquisa específica, entende-se que o pesquisador estaria apto a exercer a função de docente em curso superior 1 . Essa relação entre pesquisa e ensino é completada quando se inclui a prática profissional. A atividade profissional pode ser aliada à atuação do docente em projetos de extensão ou por meio de atividades conjuntas entre docente, bibliotecário e estudante.

Experimentar práticas com o profissional catalogador, pensando e refletindo sobre o fazer aliado aos conceitos e instrumentos em um projeto propicia uma reflexão sobre a elaboração de registros bibliográficos e possibilita uma troca entre estudante, docente e profissional. A validação da atuação conjunta entre esses três atores é evidenciada no trabalho de Hillesheim e Fachin (2016) que utilizam a própria biblioteca da universidade para propiciar um ambiente integrado entre ensino e prática, durante a disciplina regular do curso

\footnotetext{
1 Embora existam concursos públicos no nível de mestrado, a maioria ocorre no nível de doutorado nas universidades públicas. Esse assunto será retomando na seção 4 desse artigo.
} 
de graduação em Biblioteconomia.

Machado, Helder e Couto (2007) também relatam a experiência integradora entre uma disciplina obrigatória e o estágio curricular na formação do catalogador. Ressaltam que é necessário estimular a educação continuada e que o estágio curricular supervisionado é um espaço de aproximação entre a teoria e prática. Observa-se, portanto, que a formação está além das paredes da sala de aula, com o professor.

A discussão sobre educação continuada, embora esteja ganhando mais força e encontre respaldo em experiências acadêmicas, ainda precisa alcançar a comunidade profissional. Castro e Santos (2013) realizaram uma pesquisa que evidenciou que os bibliotecários e órgãos de classe não reconheceram a necessidade de educação continuada. Porém, a pesquisa aponta a necessidade de estudos continuados, por isso, recomendam a promoção de curso lato sensu.

A proposta de curso lato sensu e de cursos de extensão parece ir ao encontro das necessidades atuais, pois uma disciplina curricular de graduação não conseguiria acolher tamanhas mudanças vivenciadas desde final do século $X X$ até os dias de hoje. "Aliás, deve-se observar que a mais de 50 anos a catalogação está em mudanças. Ser catalogador não é um desafio, é um aprendizado persistente" (SILVA, 2016, p. 152).

A Representação Descritiva tem absorvido muitas ferramentas tecnológicas, consolidando e desenvolvendo modelos conceituais. Ultimamente os elementos descritivos podem ser atribuídos com base em diferentes instrumentos normativos (códigos, formatos) e podem ser alimentados em diferentes sistemas, que juntos devem funcionar propiciando a informação mais adequada ao usuário. Nesse contexto, a interoperabilidade passou a ser um termo recorrente, substituindo a padronização única e universal que imperou durante algum tempo na Catalogação.

Comunidades especializadas com uma visão diferente e de acordo com as necessidades de seus usuários não teriam outra alternativa do que criar novos elementos de dados (com diferentes relacionamentos para entidades FRBR) para expressar seus metadados (CASTRO; SANTOS, 2014, p. 20).

Quando se cogita a interoperabilidade e a criação de novos metadados tem-se um cenário novo ao catalogador, pois se cobra uma postura mais ativa e 
menos submissa a um código de catalogação. Essa proposta reafirma o papel crítico e reflexivo do profissional, contrapondo-se ao estereótipo de que o catalogador apenas executa tarefas e segue regras pré-determinadas.

Entende-se que a representação descritiva é fundamental ao profissional, visto que são atribuições do bibliotecário: "e) a execução dos serviços de classificação e catalogação de manuscritos e de livros raros e preciosos, de mapotecas, de publicações oficiais e seriadas, de bibliografia e referência" (BRASIL, 1962, online²).

Nesse sentido, os projetos pedagógicos dos cursos de graduação atendem a questão de formação do catalogador, pois Castro, Sales e Simionato (2016) identificaram que todos os cursos de graduação por eles analisados possuem a disciplina de catalogação. Porém, há variações relacionadas a terminologia, carga horária e conteúdo. Nesse ponto, cabe lembrar que Mey e Moreno (2012), entre outros pontos, afirmam que a carga horária da disciplina de catalogação deveria ser de pelo menos 120 horas, uma carga horária inferior a essa poderia comprometer a formação do futuro catalogador.

Em um primeiro momento, poderia ser considerado que a disciplina nos cursos seria suficiente para garantir $\mathrm{o}$ aprendizado necessário. Mas ao identificar que a formação envolve ensino, pesquisa e aproximação com o mercado de trabalho, observa-se que o para se formar um catalogador é preciso ir além de disciplinas obrigatórias, é necessário explorar todos os componentes curriculares previstos no projeto pedagógico de cada curso. Anna (2018) reafirma o compromisso da docência em atuar no ensino, pesquisa e extensão, assim como ampliar as formas tradicionais de ensino apostando na troca de experiências entre estudantes e professores.

Com o intuito de exemplificar as questões relacionadas ao ensino e aprendizagem de representação descritiva para além da aplicação de regras, a seguir será exposto um conteúdo específico das disciplinas de catalogação e que também está presente nos instrumentos normativos: a entidade coletiva.

\footnotetext{
2 Embora a norma para citações da ABNT indique o número da página como um elemento obrigatório para citações diretas, o documento citado não possui paginação e está disponibilizado em uma página eletrônica; por isso optou-se em indicar online nesses casos.
} 
Acredita-se que com esse exemplo se possa discutir tantos aspectos culturais como normativos, ponderando sobre questões de ensino e aprendizado na contemporaneidade.

\section{A ENTIDADE COLETIVA: SUAS CARACTERÍSTICAS}

Após apresentar uma breve discussão sobre o ensino e aprendizagem relacionada à Representação Documental, especificamente à Representação Descritiva, optou-se por utilizar como exemplo o ensino e aprendizagem da entidade coletiva. Acredita-se que utilizar um exemplo concreto ajudará a construir um diálogo ponderando questões relacionadas ao ensino e aprendizagem no cenário atual.

Mesmo abordando um conteúdo bem específico, a entidade coletiva pode ser estudada sobre vários olhares e recortes. Poderia, por exemplo, se discutir os limites de sua responsabilidade, escolha e forma de padronização de pontos de acesso, abordar os diferentes tipos de entidades existentes etc. Aqui abordaremos alguns desses pontos, mas sempre tentando contribuir para uma análise mais reflexiva sobre a entidade coletiva.

A definição para entidade coletiva mais recentemente apresentada em âmbito internacional está presente na Declaração dos Princípios Internacionais de Catalogação (ICP), publicada em 2016 com tradução para português em 2018: "Entidade coletiva - uma organização ou grupo de pessoas e/ou de organizações que se identifica por um nome específico e que atua como uma unidade (IFLA, 2016, p. 15).

Embora em sua definição não esteja contemplada o seu possível papel de autoria, cabe lembrar que a ICP não possui o termo "autor" em seu glossário, há o termo "Criador - Uma pessoa, família ou entidade coletiva responsável pelo conteúdo intelectual ou artístico de uma obra" (IFLA, 2016, p. 14). Indicando que uma entidade coletiva poderia criar uma obra, portanto, assumindo a função de autor.

A concepção mais usual sobre a responsabilidade de uma obra é bem abrangente, incluindo tanto pessoa como entidade coletiva sob o termo "autor". A concepção ampla para o termo autor foi concebida por Cutter (1876, p. 10, 
tradução nossa):

Autor, no sentido restrito, é a pessoa que escreve um livro, em um sentido mais amplo, pode ser aplicada àquele que é a causa da existência do livro reunindo textos de vários autores (normalmente chamado de editor, mais propriamente para ser chamado de compilador). Entidades coletivas (sociedades, cidades, órgãos legislativos, países) devem ser consideradas autores de suas memórias, transações, diários, debates, relatórios etc. ${ }^{3}$

Portanto, têm-se dois sentidos para designar um autor: um restrito, pois apenas alguém pode de fato criar algo (desconsiderando aqui os avanços no que tange a inteligência artificial); e um sentido amplo, que considera que uma entidade coletiva pode ser considerada também como "autora" de uma obra. Em termos conceituais, entende-se que em alguns casos a entidade coletiva seria a responsável, por isso o que denominamos hoje como ponto de acesso preferido seria atribuído à entidade coletiva. Mas o que deveria ser considerado para tal determinação? Seriam as normas ou orientações de códigos de catalogação, como veremos adiante, na próxima seção.

Para Pettee (1985), foi Cutter quem estendeu o conceito de autor,

O que Jewett incorporou na sua Regra XXII, Cutter, em sua primeira direção, reafirma na forma de uma lei geral, especificamente estendendo o princípio de autoria para entidades coletivas [...]. Cutter vai mais longe. Formas de autoria, nome pessoal, corporativo ou convencional como substituto para o autor, são fundamentais para suas regras de autor. Estas formas de autoria reúnem unidades literárias. Encontramos em Cutter, fixado para a posteridade, creio eu, os dois princípios fundamentais do catálogo de autor moderno:

1. O catálogo de autor é mais do que uma lista para encontrar um livro em particular ou disperso. Trata-se de unidades literárias e sua função é reunir sob um cabeçalho conveniente todos os assuntos ou formas de uma mesma unidade literária.

2. O método mais satisfatório de fazer isso é através da atribuição de autoria, usando como cabeçalho o nome da pessoa ou da entidade coletiva responsável pela obra, ou usar como um substituto para o cabeçalho de autor, não um nome convencional derivado da página de rosto, mas a partir da fonte literária do

\footnotetext{
3 "Author, in the narrower sense, is the person who writes a book; in a wider sense it may be applied to him who is the cause of the book's existence by putting together the writings of several authors (usually called the editor, more properly to be called the collector). Bodies of men (societies, cities, legislative bodies, countries) are to be considered the authors of their memoirs, transactions, journals, debates, reports, \&c." (CUTTER, 1876, p. 10).
} 
livro ou documento 4 (PETTEE, 1985, p. 83-84, tradução nossa).

Infere-se que a motivação da inclusão da entidade coletiva sob o rótulo de autor de uma obra tenha sido justificada por diferentes fatores. Estabelecer a autoria para uma entidade coletiva permitiria a busca e recuperação em catálogos, por exemplo. Lembre-se que até meados e final do século XX existiam apenas catálogos manuais, predominantemente em fichas com apenas 3 tipos de pontos de acesso: responsabilidade (compunham o catálogo de autor), título (compunham o catálogo de título) e o de assunto (compunham o catálogo de assunto). Esses pontos de acesso poderiam formar catálogos de busca específico ou estarem todos agregados no denominado catálogo dicionário. Então, considerar a entidade coletiva como autor tem um caráter de promover o acesso e organização dos registros. Sendo assim, ampliar o conceito de autoria nos catálogos foi a solução encontrada naquele momento para possibilitar 0 estabelecimento de pontos de acesso, proposta essa reafirmada na recente ICP:

Como pontos de acesso de dados bibliográficos se deve incluir [...] os pontos de acesso autorizados para os criadores das obras.

Deve-se considerar uma entidade coletiva como a criadora de obras que expressam o pensamento coletivo ou atividade da entidade ou quando a formulação do título, em conjunto com a natureza da obra, implique claramente que a entidade coletiva é responsável coletivamente pelo conteúdo da obra. Isso se aplica inclusive se a obra estiver assinada por uma pessoa em caráter de representante ou funcionário de uma entidade coletiva (IFLA, 2016, p. 8).

Esse fato aliado à multiplicação dos documentos tornou-se necessário para desenvolver mecanismos para detalhar a representação a fim de se identificar o documento a ser recuperado. A autoria é fundamental para a identificação de uma obra em meio a diversas sobre o mesmo assunto. "Não

\footnotetext{
4 "What Jewett embodied in his Rule XXII, Cutter, in his first direction, restates in the form of a general law, specifically extending the authorship principle to corporate bodies [...]. Cutter goes farther. Authorship forms, personal, corporate, or conventional name as substitute for author, are fundamental to his author rules. These authorship forms assemble literary units. We find in Cutter, fixed for all time, I believe, the two fundamental principles of the modern author catalog: 1. The author catalog is more than a finding list of separate and particular books. It deals with literary units and its function is to assemble under a convenient heading all issues or forms of the same literary unit. 2. The most satisfactory method of doing this is through the attribution of authorship, using as heading the name of the person, or corporate body responsible for the work, or using as a substitute for author heading, a conventional name not derived from the titlepage but from the literary source of the book or document" (PETTEE, 1985, p. 84).
} 
somente exigia-se que livros fossem rapidamente encontrados por autor e assunto, mas uma distinção teve que ser feita entre autores com mesmo nome"5 (PETTEE, 1985, p. 79, tradução nossa). E esse nome, além de nomes pessoais, incluem também os nomes das entidades coletivas. Esse controle é realizado por meio do registro de autoridade e catálogos de autoridades.

Ao incluir a identificação da autoria e o controle da forma que seu nome será representado, o registro bibliográfico torna-se mais eficiente, permitindo a recuperação, a identificação e a seleção de documentos de maneira mais precisa. Porém, nem todos os autores consentem em incluir a entidade coletiva como autora de uma obra. Wajenberg (c1989) prefere não a incluir.

Não é minha intenção descartar a possibilidade de autoria corporativa, e eu não teria nenhuma objeção a ampliar a definição de modo a incluir entidade coletiva com pessoa como autores. No geral, no entanto, eu preferiria não considerar entidade coletiva como autor, por razões que não têm nada a ver com os conceitos de autoria [...]. Se entidades coletivas são autores, eles não são muito úteis, e eu prefiro não dar-lhes este status $^{6}$ (WAJENBERG, c1989, p. 25, tradução nossa).

Para este autor, o catalogador deve direcionar a sua atenção ao documento, ao universo bibliográfico. Nesse contexto, ele recomenda a seguinte definição de autor: "Um autor de uma obra é uma pessoa identificada como um autor em itens que contêm a obra e/ou na literatura secundária que menciona a obra"7 (WAJENBERG, c1989, p. 24, tradução nossa).

A identificação da autoria deve ser considerada de modo amplo (como proposto por Cutter, acima citado), porém sob o termo responsabilidade, pois poderia abarcar uma série de funções que não somente a de autor (SILVEIRA, 2013). O termo "responsável" parece ser mais adequado, uma vez que uma

\footnotetext{
5 "Not only the ready finding of books by author and subject was demanded but a distinction had to be made between author the same name" (PETTEE, 1985, p. 79).

6 "It is not my intention to rule out the possibility of corporate authorship, and I would have no objection to expanding the definition to include corporate bodies with person identified as authors. On the whole, however, I would prefer not to regard corporate bodies as author, for reasons that have nothing to do with the concepts of authorship [...] If corporate bodies are author, they are not very usefull ones, and I would prefer not given them that status" (WAJENBERG, c1989, p. 25).

7 "an author of a work is a person identified as an author in items containing the work, and/or in secondary literature that mentions the work" (WAJENBERG, c1989, p. 24).
} 
entidade coletiva não possui capacidade cognitiva de ser autor de algo, porém tem embasamento para ser responsável por determinados documentos.

Alguns documentos são mais fáceis de se identificar que a entidade coletiva de fato seria a responsável e assim determinar o ponto de acesso preferido. Por exemplo, uma legislação federal; é mais fácil entender que uma Lei federal tenha seu ponto de acesso pela federação, no caso Brasil. Porém existem alguns documentos que podem gerar dúvidas sobre o que fato seria 0 limite entre a entidade coletiva ser a autora ou a editora de uma determinada obra. E para isso existem uma série de orientações em códigos de catalogação para direcionar o estabelecimento de pontos de acesso preferido para uma entidade, em diferentes tipos de documentos.

As entidades coletivas, portanto, possuem características bem amplas, pois buscam abarcar uma variedade muito grande de organizações e grupos. Porém, como contraponto, as entidades coletivas também abordam muitas especificidades. Por exemplo, o conhecimento indígena de uma comunidade específica pode ser representado a partir da padronização daquele Povo Indígena (FRANCA, 2016).

Nesse sentido, mesclando o amplo e o específico temos sob "entidade coletiva" desde instituições formalizadas como universidades, países e até grupos de pessoas, que adotam um termo que os identifica por meio de uma coletividade. Com tantos olhares sobre o termo entidade coletiva, sua complexidade de interpretação e identificação de seu papel na produção de um determinado documento, temos como reflexão como deve ser o ensino e aprendizagem desse conteúdo durante a graduação.

[...] o tratamento da informação não se dissocia dos contextos culturais de produção e uso de conhecimento, demandando a combinação de referências da produção informacional, dos objetivos institucionais e dos elementos cognitivos e comunicacionais dos públicos da informação, como meio de otimizar a circulação social da informação (ORTEGA; LARA, 2010, online).

Sendo assim, conhecer e identificar o documento a ser representado e seus responsáveis vai além de ler e aplicar uma regra. Para se representar é necessário se compreender todo o contexto de produção de um conhecimento. No caso da entidade coletiva, utilizando o exemplo de conhecimento indígena, 
se o catalogador não compreender como se constrói um conhecimento indígena, provavelmente não representará como sendo o responsável intelectual de um documento o Povo indígena. Essa ausência de reconhecimento do Povo como criador daquele conhecimento implica em não representar a sociedade, portanto, não está exercendo seu papel social.

Essa discussão do papel social e o catalogador será continuado na seção a seguir, fazendo relação entre questões de conteúdo propriamente dito com papéis sociais que devem desempenhar o profissional e a legislação relacionado ao ensino superior em Biblioteconomia.

\section{O ENSINO E APRENDIZAGEM EM TEMPOS DE PANDEMIA}

Um olhar restrito ao conteúdo a ser ministrado em Representação Descritiva não pode ser omisso em fazer uma reflexão crítica do papel do bibliotecário na sociedade. Seguindo essa linha de pensamento, nesta seção serão feitas referências ao conteúdo das questões normativas que guiam o ensino superior brasileiro.

Algumas questões identificadas na seção 2 deste texto seriam sanadas com a consulta na legislação. Por exemplo, a presença da articulação entre ensino, pesquisa e extensão na área a ser exercida pelo docente de instituições públicas federais está prevista na Lei № 12.772, de 28 de dezembro de 2012, a saber:

Art. 8ㅇ $\mathrm{O}$ ingresso na Carreira de Magistério Superior ocorrerá sempre no primeiro nível de vencimento da Classe A, mediante aprovação em concurso público de provas e títulos [...]

$\S 1^{\circ} \mathrm{O}$ concurso público de que trata o caput tem como requisito de ingresso o título de doutor na área exigida no concurso.

[...]

Art. 20. O Professor das IFE, ocupante de cargo efetivo do Plano de Carreiras e Cargos de Magistério Federal, será submetido a um dos seguintes regimes de trabalho:

I - 40 (quarenta) horas semanais de trabalho, em tempo integral, com dedicação exclusiva às atividades de ensino, pesquisa, extensão e gestão institucional; (BRASIL, 2012, online).

Sendo assim, a maior parte dos docentes nas instituições de ensino são docentes com dedicação exclusiva, portanto, devem exercer atividades de 
ensino, pesquisa e extensão em suas respectivas áreas de atuação, previstas no concurso. A lacuna identificada na pesquisa em Representação Descritiva deve ser melhor analisada, verificando nos concursos realizados a formação do docente.

Nesse ponto, considera-se a formação do docente norteadora do processo de ensino e aprendizagem em representação descritiva, pois a formação do catalogador inicia-se na graduação. Se o docente não pesquisa a área, dificilmente incentivará o estudante na iniciação à pesquisa científica, pois ele mesmo não terá pesquisa em andamento para acolher o estudante.

Uma vez posto a questão da pesquisa, ressalta-se que a extensão pode ser o grande elo de contato com a sociedade e também com a prática profissional (além dos estágios curriculares e supervisionados). O Plano Nacional de Educação (BRASIL, 2001) prevê que 10\% da carga horária total dos cursos de graduação seja contabilizado em ações de extensão. Essa proposta oferece um contato com a sociedade, portanto, inserir o estudante como um agente social que retribui à sociedade o investimento nele depositado. Também pressupõe uma visão além dos muros e o contato sociocultural como um elemento fundamental para a formação.

A proposta de uma integração com a sociedade permeia princípios educadores, como o apontado por Freire (1996), que reafirma que ensinar não é transmissão do conhecimento e sim construção e que o sujeito deve ser capaz de inteligir e comunicar o inteligido. Por isso, o contato com a sociedade externa à universitária é uma ação de troca e permite ao estudante aplicar seus conhecimentos e adquirir conhecimentos além da sala de aula tradicional.

Os desafios de ensino e aprendizagem em representação descritiva abarcam tanto questões de mudanças da própria área, com conteúdos novos e tecnologia de informação, como ausência de pesquisa no âmbito de pósgraduação e o próprio momento pandêmico atual.

Durante o ano de 2020, com a pandemia causada pela covid-19, o Ministério da Educação (BRASIL, 2020) autorizou o ensino remoto para os cursos de graduação, porém, diante do cenário de dificuldade de acesso aos instrumentos adotados em sala de aula presencial causou um certo alvoroço na 
área.

Se até então critica-se o uso excessivo de aplicação de regras nas disciplinas de Representação Descritiva, a pandemia apresentou obstáculos, entre eles o próprio acesso ao Código de Catalogação Anglo-Americano, cuja tradução é utilizada apenas pelo meio impresso, sem possibilidade de assinatura digital. Enquanto que a normativa Recurso: descrição e acesso (RDA) possui assinatura online, porém os cortes orçamentários não permitem seu uso em grande escala aos estudantes de graduação.

Nesse caso, como ministrar o conteúdo que até então era pautado majoritariamente na aplicação de normativas sem possibilitar o acesso a elas? A retomada do ensino conceitual e teórico tão discutido nos últimos anos no Brasil, como apresentado anteriormente na seção 2, parece ter ganhado espaço com a dificuldade do acesso ao código.

Retomamos o exemplo das entidades coletivas, podemos dizer que a falta de acesso ao código impossibilita o ensino das regras para estabelecimento e representação das entidades em registro bibliográficos e de autoridade, porém abre um caminho para o estudo teórico e conceitual sobre a catalogação como um todo.

Interessante observar nesse cenário cada vez mais digital o esforço por se padronizar "entidades coletivas" em bases de dados para desenvolver e validar indicadores. Por exemplo, a Web of Science (2020) apresenta um controle da forma adotada no campo "nome da organização", no qual exibe o nome preferencial da organização e também indicam os termos alternativos (as famosas remissivas). Esse controle no campo permite evidenciar a publicação institucional das entidades coletivas, dando respaldo e criando rankings. Nesse caso, a análise sobre a entidade coletiva e o seu controle e representação ultrapassam as barreiras de Organização e Representação e podem resultar em indicadores a serem utilizados para distribuição de verbas e fomentos.

As diretrizes curriculares orientam que cada instituição elabore seus projetos pedagógicos de acordo com vários elementos, entre eles a inserção regional e o perfil dos egressos. Tais diretrizes curriculares consideram que o curso deve atender a especificidades regionais, por isso estabelecer um currículo 
mínimo como antes, indicando quais disciplinas um curso de graduação deveria ministrar iria em uma direção contrária às próprias diretrizes.

A Resolução CNE/CES no 19, de 13 de março de 2002 estabelece as Diretrizes Curriculares para os cursos de Biblioteconomia, incluindo como elementos a serem considerados no projeto pedagógico:
a) o perfil dos formandos;
b) as competências e habilidades gerais e específicas a serem desenvolvidas;
c) os conteúdos curriculares de formação geral e os conteúdos de formação específica ou profissionalizante;
d) o formato dos estágios;
e) as características das atividades complementares;
f) as estruturas do curso;
g) as formas de avaliação (BRASIL, 2002, p. [1])

Com essa estrutura, cada instituição consegue desenhar um projeto pedagógico de acordo com a sua necessidade e demanda, abrindo um leque de oportunidades que envolvem ensino, pesquisa e extensão. Destaca que a formação profissional e a execução de atividades consideradas técnicas, como a catalogação, não constam como prioritárias na formação do bibliotecário. Ela pode ser um elemento, mas "treinar" um aluno com foco apenas na sua absorção do mercado de trabalho não faz parte da estrutura atual de um ensino superior.

As disciplinas de catalogação e o próprio campo de estudo, talvez por ter poucas teses e dissertações defendidas ou por ser considerada muito tecnicista por alguns, podem passar a impressão de que seu ensino devesse ser pautado na utilização e aplicação de regras.

Porém, ao analisar as normativas que regem o ensino superior e as próprias demandas da área encontramos um terreno fértil para discussões conceituais e sociais. Desde $2002 \mathrm{com}$ as diretrizes curriculares e posteriormente em 2012 com o plano de carreira docente, fica evidente a necessidade de se repensar o ensino superior, além da formação de um profissional. É preciso formar sujeitos ativos, inseridos em contextos socioculturais e políticos.

\section{CONSIDERAÇÕES FINAIS}

No que tange ao ensino de Biblioteconomia, têm-se muitos estudos que 
abordam e ressaltam o papel social do bibliotecário. O desafio está em aliar todas as mudanças tecnológicas com as demandas sociais.

Em uma sociedade múltipla e em constante alteração, a formação do curso superior, realizada em geral com 4 anos de duração, parece não ser mais suficiente para contemplar os conteúdos necessários para o fazer profissional. A proposta seria em ofertar cursos de educação continuada de pós-graduação (lato sensu), cursos de curta duração por meio da extensão universitária e fortalecer a pesquisa stricto sensu.

O momento parece propício para se refletir sobre as perspectivas para a Representação Documental, incluindo os conteúdos tradicionais e emergentes, o tempo é de reaprendizagem para os docentes e também para os discentes e profissionais graduados.

No que se refere à reflexão sobre entidades coletivas, observa-se que ela pode ser um exemplo a ser discutido e apresentado aos discentes de graduação, valorizando o esforço intelectual, conceitual e teórico que é experimentado na Representação Descritiva. Para se representar e organizar, assim como para se estabelecer e aplicar normativas, é preciso conhecer o documento e o contexto de sua produção.

Sendo assim, o cenário de pandemia causado pela covid-19, que alterou a educação do modo presencial para o remoto, não provocou mudanças bruscas, apenas está proporcionando a discussão levantada anos anteriores sobre o ensino e a aprendizagem pautada prioritariamente na prática de uso de código de catalogação para o resgate de discussão e papel social da Representação Descritiva e do bibliotecário para seu papel social. A dificuldade enfrentada pela adoção remota de materiais didáticos encontrados apenas em formato impresso reacendeu a discussão no âmbito da catalogação, especificamente no ensino de graduação, sobre quais conteúdos são essenciais e o que deve ser abordado e priorizado no ensino remoto.

Por fim, embora a discussão sobre o papel social da catalogação e a importância de sua contextualização sociocultural seja antiga, devido às mudanças tecnológicas e ao desenvolvimento de vários instrumentos e normativas na área, aliada ao ensino remoto causado pela pandemia, acredita- 
se que deve ser um trabalho integrado entre ensino, pesquisa e extensão, iniciado especialmente nos estudantes de graduação. A formação do bibliotecário requer características múltiplas e para alcançá-las deve-se explorar todos os elementos propostos do projeto pedagógico, desde disciplinas obrigatórias até as atividades de extensão.

\section{REFERÊNCIAS}

ANNA, J. S. Ensino pela pesquisa na docência universitária: um relato de experiência na disciplina de catalogação. Revista Brasileira de Educação em Ciência da Informação, v. 5, n. 1, p. 76-88, 2018. Disponível em: https://brapci.inf.br/index.php/res/v/72081. Acesso em: 27 set. 2020.

BRASIL. Lei N. 4.084, de 30 de junho de 1962. Brasília: Presidência da República, 1962. Disponível em: http://www.planalto.gov.br/ccivil_03/leis/19501969/14084.htm\#: :text=Art\%206\%C2\%BA\%20S\%C3\%A30\%20atribui\%C3\%A 7\%C3\%B5es\%20dos,\%C3\%A0s\%20mat\%C3\%A9rias\%20e\%20atividades\%20 seguintes\%3A\&text=d)\%20a\%20organiza\%C3\%A7\%C3\%A30\%20e\%20dire\% C3\%A7\%C3\%A30\%20dos\%20servi\%C3\%A7os\%20de\%20documenta\%C3\%A 7\%C3\%A3o. Acesso em: 27 set. 2020.

BRASIL. Lei № 10.172, de 9 de janeiro de 2001. Brasília: Presidência da República, 2001. Disponível em: http://www.planalto.gov.br/ccivil_03/leis/leis_2001//10172.htm. Acesso em: 27 set. 2020.

BRASIL. Lei № 12.772, de 28 de dezembro de 2012. Brasília: Presidência da República, 2012. Disponível em: http://www.planalto.gov.br/ccivil_03/_ato20112014/2012/lei/l12772.htm. Acesso em: 27 set. 2020.

BRASIL. Ministério da Educação. Portaria n. 343, de 17 de março de 2020. Brasília: DOU, 2020. Disponível em: https://www.in.gov.br/en/web/dou//portaria-n-343-de-17-de-marco-de-2020-248564376. Acesso em: 27 set. 2020.

BRASIL. Ministério da Educação. Resolução CNE/CES 19, de 13 de março de 2002. Brasília: MEC, 2002. Disponível em: http://portal.mec.gov.br/cne/arquivos/pdf/CES192002.pdf. Acesso em: 29 set. 2020.

CASTRO, C. A. O ensino e a prática da biblioteconomia na Era das incertezas. ETD - Educação Temática Digital, v. 6, n. 2, p. 17-29, 2005. https://periodicos.sbu.unicamp.br/ojs/index.php/etd/article/view/771/786. Acesso em: 29 set. 2020. 
CASTRO, F. F.; SALES, A. R. S.; SIMIONATO, A. C. Recomendações teóricas e práticas para o ensino da catalogação no brasil. Encontros Bibli: Revista Eletrônica de Biblioteconomia e Ciência da Informação, v. 21, n. 46, p. 19-32, 2016. Disponível em: https://periodicos.ufsc.br/index.php/eb/article/view/15182924.2016v21n46p19. Acesso em: 27 set. 2020.

CASTRO, F. F.; SANTOS, P. L. V. A. C. Elementos de interoperabilidade na perspectiva da catalogação descritiva. Informação \& Sociedade: Estudos, v. 24, n. 3, 2014. Disponível em: http://hdl.handle.net/20.500.11959/brapci/92657. Acesso em: 27 set. 2020.

CASTRO, F. F.; SANTOS, S. V. Educação continuada em catalogação descritiva: um olhar emergente. Biblios (Peru), n. 53, p. 13-28, 2013. Disponível em: http://biblios.pitt.edu/ojs/index.php/biblios/article/view/133. Acesso em: 27 set. 2020.

CUTTER, C. A. Rules for a dictionary catalogue. Washington: G.P.O., 1876. Disponível em: http://www.archive.org/details/cu31924029518978. Acesso em: 28 set. 2020.

FRANCA, A. da S. Do cocar ao catálogo: a representação bibliográfica da autoria indígena no Brasil. 2016. Dissertação (Mestrado) - Universidade Federal do estado do Rio de Janeiro, Rio de Janeiro, 2016. Disponível em: http://www.unirio.br/ppgb/arquivo/aline-franca/view. Acesso em: 27 set. 2020.

FRANCELIN, M. M. Tópicos para a iniciação à pesquisa científica na Ciência da Informação. In: SILVA, J. F. M. da; PALETTA, F. C. (org.). Tópicos para ensino de Biblioteconomia. São Paulo: ECA/CBD - USP, 2016. v. 1, p. 140150.

FREIRE, P. Pedagogia da autonomia: saberes necessários à prática educativa. 30. ed. São Paulo: Paz e Terra, 1996. (Coleção Leitura).

HILLESHEIM, A. I. A.; FACHIN, G. R. B. Prática de tratamento da informação: relato de experiência docente. Revista ACB: Biblioteconomia em Santa Catarina, v. 21, n. 3, p. 627-638, 2016. Disponível em: http://hdl.handle.net/20.500.11959/brapci/65610. Acesso em: 27 set. 2020.

IFLA. Statement of International Cataloguing Principles (ICP). Haia: IFLA 2016. Disponível em: https://www.ifla.org/files/assets/cataloguing/icp/icp_2016pt.pdf. Acesso em: 29 set. 2020. Tradução para o português em 2018 sob a responsabilidade de Marcelo Votto Texeira e revisado por Jorge Moisés Kroll do Prado.

MACHADO, E. C.; HELDE, R. V.; COUTO, S. Ensino de catalogação: da teoria à prática. Revista Brasileira de Biblioteconomia e Documentação, v. 3, n. 2, 
p. 100-106, 2007. Disponível em:

http://hdl.handle.net/20.500.11959/brapci/2431. Acesso em: 27 set. 2020.

MEY, E. S. A.; MORENO, F. P. Desafios do ensino de catalogação no Brasil. In: ENCONTRO NACIONAL DE CATALOGAÇÃO, 1.; Encontro de Estudos e Pesquisas em Catalogação, 3., 2012, Rio de Janeiro. Anais [...]. Disponível em:

http://pt.scribd.com/doc/109279226/Desafios-do-ensino-de-catalogacaonoBrasil. Acesso em: 27 set. 2020.

ORTEGA, C. D. Contexto de desenvolvimento da organização da informação, com enfoque para a catalogação, na escola de ciência da informação da UFMG. Perspectivas em Ciência da Informação, v. 18, n. 2, p. 182-215, 2013. Disponível em: http://hdl.handle.net/20.500.11959/brapci/35682. Acesso em: 27 set. 2020.

ORTEGA, C. D.; LARA, M. L. G. de. A noção de documento: de Otlet aos dias de hoje. Datagramazero, v. 11, n. 2, abr. 2010. Disponível em: https://brapci.inf.br/index.php/res/v/7087. Acesso em: 27 set. 2020.

PETTEE, J. The development of authorship rules as found in the AngloAmerican Code. In: CARPENTER, M.; SVENONIUS, E. (ed.) Foundations of cataloging: a sourcebook. Littleton, Colorado: Libraries Unlimited, 1985. Artigo originalmente publicado em Library Quarterly, v. 6, jul., 1936.

SILVA, J. F. M. da. A ISBD: um instrumento de representação descritiva em evolução. In: SILVA, J. F. M. da; PALETTA, F. C. (org.). Tópicos para ensino de Biblioteconomia. São Paulo: ECA/CBD - USP, 2016. v. 1, p. 151-165.

SILVEIRA, N. C. A trajetória da autoria na representação documental. 2013. 191 f. Tese (Doutorado) - Escola de Comunicações e Artes, Universidade de São Paulo, São Paulo, 2013.

WAJENBERG, A. S. A cataloger's view of authorship. In: SVENONIUS, E. (ed.). The conceptual foundations of descriptive cataloging. San Diego:

Academic Press, c1989. (Library and Information Science). p. 21-27.

WEB OF SCIENCE. Principal Coleção do Web of Science Ajuda. [S.I.]: Clarivate, $2020 . \quad$ Disponível em: https://images.webofknowledge.com/WOKRS514B4/help/pt_BR/WOS/hp_orga nizations_enhanced_index.html. Acesso em: 29 set. 2020.

\section{THE REPRESENTATION OF THE CORPORATE BODY: A DISCUSSION ON TEACHING AND LEARNING}

\section{ABSTRACT}


Introduction: the main theme of this text is the teaching of cataloging and has as its guiding thread an analysis of the corporate body and the necessary requirements for undergraduate in Library Science. Objective: to present research related to the teaching of cataloging and to analyze, based on the norms for Brazilian higher education, the social role of the cataloger, since its formation. Methodology: bibliographic research that critically analyzes from the student's education to the teaching performance. Results: it has been observed, for some time, that cataloging was geared to technical characteristics and that the demands and changes in the area require re-learning of teaching. Conclusions: the social role and the training of the librarianship require multiple actions and for that, one must explore all the proposed elements of the pedagogical project, from mandatory subjects to extension activities.

Descriptors: Cataloging. Corporate body. Descriptive Representation. Teaching.

\title{
LA REPRESENTACIÓN DEL AGENTE COLECTIVO: UNA DISCUSIÓN SOBRE ENSEÑANZA Y APRENDIZAJE
}

\begin{abstract}
RESUMEN
Introducción: el tema central de este texto es la enseñanza de la catalogación y tiene como hilo conductor un análisis del agente colectivo y los requisitos necesarios para el grado en Bibliotecología. Objetivo: presentar investigaciones relacionadas con la enseñanza de la catalogación y analizar, con base en las normas de la educación superior brasileña, el papel social del catalogador, desde su formación. Metodología: investigación bibliográfica que analiza críticamente desde la formación del alumno hasta el desempeño docente. Resultados: se ha observado, desde hace algún tiempo, que la catalogación estaba orientada a características técnicas y que las demandas y cambios en el área requieren un reaprendizaje de la docencia. Conclusiones: el rol social y la formación en Bibliotecología requieren múltiples acciones y para ello se deben explorar todos los elementos propuestos del proyecto pedagógico, desde las asignaturas obligatorias hasta las actividades de extensión.
\end{abstract}

Descriptores: Catalogación. Agente colectivo. Representación descriptiva. Enseñando.

Recebido em: 15/09/2020

Aceito em: 30/09/2020 